\title{
Influence of added concrete compressive strength on adhesion to an existing concrete substrate
}

\author{
Eduardo N.B.S. Júlio ${ }^{a, *}$, Fernando A.B. Branco ${ }^{b}$, Vítor D. Silva ${ }^{c}$, Jorge F. Lourenço ${ }^{d}$ \\ ${ }^{a}$ Department of Civil Engineering, University of Coimbra-Polo II, 3030-290 Coimbra, Portugal \\ ${ }^{\mathrm{b}}$ Department of Civil Engineering, IST, Av. Rovisco Pais, 1049-001 Lisbon, Portugal \\ ${ }^{\mathrm{c}}$ Department of Civil Engineering, University of Coimbra - Polo II, 3030-290 Coimbra, Portugal \\ ${ }^{\mathrm{d}}$ Department of Civil Engineering, ISEC, Rua Pedro Nunes, 3030-199 Coimbra, Portugal
}

Received 10 May 2005; received in revised form 13 June 2005; accepted 17 June 2005

\begin{abstract}
An experimental study was performed to evaluate the bond strength between two concrete layers of different ages, considering different mixtures of added concrete, with different strengths. The specimens first had the roughness of the substrate surface increased by sand blasting. Later, the new concrete was added. Afterwards, slant shear tests were performed to quantify the bond strength in shear. These tests indicated that increasing the compressive strength of the added concrete relative to the compressive strength of the substrate concrete improves the bond strength and changes the rupture mode from adhesive to monolithic. A finite element analysis showed that, increasing the difference between the compressive strengths of the added concrete and the substrate concrete, higher values of normal stress are present in the interface, for the same level of shear stress. The study presented in this paper reveals that the added concrete, normally with higher compressive strength than the substrate concrete, may possibly have an influence on concrete-to-concrete bond strength. Therefore, design of shear at the interface between concrete cast at different ages, according to Eurocode 2, could be improved, since here only the lowest strength concrete is considered.
\end{abstract}

(C) 2005 Elsevier Ltd. All rights reserved.

Keywords: Concrete; Bond; Strength

\section{Introduction}

Most repairing and strengthening techniques of RC structures include adding new concrete to an existing concrete substrate. The common practice consists of first increasing the roughness of the substrate surface [1]. In some cases, applying a bonding agent and/or applying steel connectors is also adopted before casting the new concrete. Relative to the latter, different materials and methods are considered in several published experimental studies [2].

Talbot et al. [3] studied the bonding durability of thin concrete repairs. The authors mention that an ordinary

\footnotetext{
*Corresponding author. Tel.: + 351239797258 ; fax: +351239797259 .

E-mail address: ejulio@dec.uc.pt (E.N.B.S. Júlio).
}

concrete was used on the substrate and different shotcrete mixes were used as repairing layer. Silfwerbrand [4] published a study on concrete bond in repaired bridge decks. The author indicates the constituents of the concrete used for the base layer but only refers to the added concrete as the "overlay". Hindo [5] presented a study on in-place bond testing of concrete repairs. Different bonding agents are referred to in this study: epoxy, polymer-modified cement slurry, latex/cement slurry and cement slurry. However, no information is given about concrete substrates and repairing materials. Júlio et al. [6] studied the influence of an epoxy-based bonding agent on a roughened substrate surface. The same design mixture was used for the added concrete and for the concrete substrate. Abu-Tair et al. [7] tested the bond between repair materials and concrete substrates. The authors indicate details on the mechanical 
properties of the substrate concrete and of the three repair materials: a lightweight epoxy render, a cementitious modified acrylic mortar and a laboratory-mixed concrete. Cleland and Long [8] performed pull-off tests to assess the adhesion of patch repairs. Five different repair materials were used but details about these are not provided. Saucier and Pigeon [9] studied the durability of new-to-old concrete bonding. The authors mention that only one type of concrete was used to cast both layers of the composite specimens and indicate the constituents.

Concrete jacketing is one of the most commonly used strengthening techniques of structural elements [10]. The adhesion of the added concrete to the original column is important to ensure the monolithic behaviour of the composite element. Rodriguez and Park [11] performed tests with columns strengthened by RC jacketing. The authors mention that a normal weight concrete was used on the jacket. Hayashi et al. [12] indicate that the strengthening mortar was cast under pressure into the mould. Bett et al. [13] used a shotcrete jacket to strengthen RC columns. Gomes and Appleton [14] executed the jacket with a cementitious non-shrinkable repairing mortar. Ramirez et al. [15] applied a polymeric concrete jacket. Júlio et al. $[16,17]$ used a commercial self-compacting highperformance grout. Other authors refer to the added concrete simply as "the new concrete" specifying neither its mixture design nor its casting method [18].

According to Eurocode 2 [19], the design shear resistance at the interface between concrete cast at different ages, is given by

$v_{\mathrm{Rdi}}=c f_{\text {ctd }}+\mu \sigma_{\mathrm{n}}+\rho f_{\mathrm{yd}}(\mu \sin \alpha+\cos \alpha)$,

where $c$ and $\mu$ are factors dependent on the roughness of the substrate surface; $f_{\text {ctd }}$ is the design tensile strength of the concrete with the lowest strength; $\sigma_{\mathrm{n}}$ is the stress per unit area caused by the minimum external normal force across the interface that can act simultaneously with the shear force; $\rho$ is the ratio between the area of reinforcement crossing the interface and the area of the joint; and $\alpha$ is the angle of the reinforcement crossing the interface to the latter.

Given that only the lowest strength concrete is considered in Eq. (1), the influence of the added concrete on the bond strength is not assumed. Since, in the published studies referred to, different concrete mixtures and casting methods were used, for both the substrate and the repairing/strengthening layer, the influence of the latter on the bond strength is not possible to assess. Therefore, this was defined has the major objective of the experimental research described in this paper.

\section{Experimental investigation}

Three concrete mixtures were designed, M30, M50 and M100, with previewed mean values of compressive strength of 30,50 and $100 \mathrm{MPa}$, respectively. These values correspond to standard tests of cubic specimens, stored during 28 days in conventional conditions of temperature and relative humidity, respectively, $20^{\circ} \mathrm{C}$ and $100 \% \mathrm{RH}$.

Three situations were considered: $30 / 30,30 / 50$ and $30 /$ 100 , being the first value, the designation of the concrete mixture adopted for the substrate and, the second value, the designation of the mixture adopted for the added concrete.

The slant shear test was selected to quantify the bond strength in shear, because it had been used with excellent results in previous studies by the authors on concrete-toconcrete bond strength $[6,16,20]$. The adopted geometry for the specimens was a $20 \times 20 \times 40 \mathrm{~cm}^{3}$ prism with the interface line at approximately $30^{\circ}$ to the vertical. The specimens were tested under compression using the standard procedure for the testing of cubes or cylinders for compressive strength.

For each considered situation, 5 slant shear specimens were built as well as 6 standard specimens to characterize the compressive strength of the concrete substrate and of the added concrete ( 3 cubes for each).

The treatment of the substrate surface was adopted based on previous slant shear tests performed by the authors, considering different methods for preparing the substrate surface [20]. Since sand-blasting was the preparation method that presented the best results, it was adopted for all specimens used in the experimental study herein described.

Also, based on results of other tests performed by the authors [16], the original concrete age and the added concrete age were set at 112 and 28 days, respectively, at the time of the test, to ensure the existence of differential shrinkage.

\section{Concrete mixture design method}

The different concrete mixtures used in this study were designed based on the absolute volume expression [21]:

$(c+s)+\sum \mathrm{ag}+(w+\mathrm{ad})+\mathrm{vv}=1$,

where $c$ is the absolute volume of cement, $s$ is the absolute volume of the adopted addition, $\sum$ ag is the sum of the absolute volume of aggregates, $w$ is the water volume of the mixture, ad is the volume of the admixture used and $\mathrm{vv}$ is the void volume, for unit of apparent volume of concrete. 
The class and type of cement was defined according to the wanted compressive strength. Portland cements type II 32.5, type I 32.5 and type I 52.5 were adopted for M30, M50 and M100 mixtures, respectively. Only one addition of silica fume was adopted, for M100 mixture, considering that its efficiency varies between $10 \%$ and $20 \%$ [22-24].

Aggregates have also been selected in function of the compressive strength defined for each concrete due to their influence [25-27]. In M30 and M50 mixtures limestone crushed aggregates were used and in M100 mixture, granitic crushed aggregates were adopted. In all mixtures natural siliceous sand was used.

Different admixtures were introduced to change the rheology of fresh concrete. Since concrete compressive strength and workability vary in opposite ways, the objective of using these products was to achieve the wanted compressive strength with adequate values of the other parameter. Furthermore, when a silica fume addition is used, a super-plasticizer is needed [28,29].

The cement or binder dosage was assessed using the Feret expression:

$f_{c, j}=k_{1, j} \times \gamma^{2}$,

where $f_{c, j}$ is the compressive strength of concrete with $j$ days of age, $\gamma$ is the compactness of the fresh binder paste and $k_{1, j}$ is a coefficient associated to the latter that can be determined in function of cement characteristics and efficiency of chosen addition percentage.

The design of the mixture that gives concrete the previewed compactness, for the imposed casting conditions, was performed by the Faury method, adjusting the mixture curve with a reference granulometric curve.

Relative to the void volume, the values of ACI 613 [30] were adopted, defined in function of maximum dimension of the aggregates set used [21]. The water of the mixture was determined with the expression [21]

$w=I-\mathrm{vv}-\mathrm{ad}$,

where $I$ is the void index given by Faury expression.

The last step was the execution of an experimental mixture to verify if the defined characteristics were fulfilled. Several characteristics of the fresh concrete were considered. In some cases the calculated compactness did not correspond to the real value and adjustments had to be made. When results were satisfactory, tests on hardened concrete were conducted to evaluate the compressive strength at different ages. Again, in some cases, corrections had to be implemented. The constituents of the adopted mixtures, M30, M50 and M100, are given in Table 1.

\section{Results and discussion}

In Table 2 are expressed the mean values of the compressive strength of the substrate concrete, the
Table 1

M30, M50 and M100 mixtures

\begin{tabular}{|c|c|c|c|c|}
\hline \multicolumn{2}{|l|}{ Constituents $\left(/ \mathrm{m}^{3}\right)$} & M30 & M50 & M100 \\
\hline \multicolumn{5}{|l|}{ Portland cement $(\mathrm{kg})$} \\
\hline Type II:32.5 & & 310 & - & - \\
\hline Type I:32.5 & & - & 360 & - \\
\hline Type I:52.5 & & - & - & 500 \\
\hline Silica fume (kg) & & - & - & 100 \\
\hline \multicolumn{5}{|l|}{ Admixture (1) } \\
\hline $\begin{array}{l}\text { Modified sulphonated } \\
\text { melamine methanal } \\
\text { condensate }\end{array}$ & & 3.1 & & \\
\hline Modified & & & 1.6 & \\
\hline \multicolumn{5}{|l|}{ lignosulphonate } \\
\hline $\begin{array}{l}\text { Sulphonated melamine } \\
\text { methanal condensate }\end{array}$ & & & & 12.0 \\
\hline Water (l) & & 177 & 168 & 163 \\
\hline Aggregates (kg) & $\begin{array}{l}\text { Fineness } \\
\text { modulus }\end{array}$ & & & \\
\hline Siliceous sand & 2.84 & 913 & 813 & 638 \\
\hline $\begin{array}{l}\text { Limestone crushed fine } \\
\text { aggregates }\end{array}$ & 6.16 & 458 & 469 & - \\
\hline $\begin{array}{l}\text { Limestone crushed } \\
\text { coarse aggregates }\end{array}$ & 6.93 & 478 & 567 & - \\
\hline $\begin{array}{l}\text { Granitic crushed fine } \\
\text { aggregates }\end{array}$ & 5.88 & - & - & 938 \\
\hline
\end{tabular}

compressive strength of the added concrete, the bond strength in shear of the interface of slant shear specimens, respecting the three situations considered, and the corresponding standard deviation and variation coefficient.

All 30/30 specimens showed an adhesive rupture mode (Fig. 1). A different result was observed with all $30 / 50$ specimens and all 30/100 specimens, which exhibited a monolithic rupture mode (Fig. 2). For this reason, values presented for these last situations must be considered as a lower estimate of the bond strength in shear of their interfaces.

To understand the reasons for this change in the rupture mode, a numerical analysis was performed, using the finite element method, in order to obtain the stress distribution at the interface. A mesh of 2048 plane stress, 8 nodes, isoparametric elements was used (Fig. 3). This mesh was selected from a set of meshes of increasing number of elements, since the corresponding results did not differ from those obtained with a more refined mesh. To accurately simulate the effect of the testing machine, a vertical displacement was imposed to the base of the slant shear specimens, corresponding to the average rupture load of each considered situation. Displacements were restrained at both ends. For this evaluation, linear elastic material behaviour was assumed and the modulus of elasticity was determined 
Table 2

Average results of slant shear and compressive tests of situations $30 / 30,30 / 50$ and 30/100

\begin{tabular}{|c|c|c|c|c|}
\hline & Rupture mode & Compressive/bond strength (MPa) & Standard dev. (MPa) & Variation coefficient $(\%)$ \\
\hline \multicolumn{5}{|c|}{ Substrate concrete } \\
\hline $30 / 30$ & & 37.73 & 0.23 & 0.61 \\
\hline $30 / 50$ & - & 33.53 & 0.34 & 1.01 \\
\hline $30 / 100$ & & 33.09 & 1.56 & 4.71 \\
\hline \multicolumn{5}{|c|}{ Added concrete } \\
\hline $30 / 30$ & & 35.37 & 1.37 & 3.87 \\
\hline $30 / 50$ & - & 45.61 & 2.15 & 4.71 \\
\hline $30 / 100$ & & 91.25 & 4.35 & 4.77 \\
\hline \multicolumn{5}{|c|}{ Slant shear tests } \\
\hline $30 / 30$ & Adhesive $^{\mathrm{a}}$ & 13.01 & 0.50 & 3.84 \\
\hline $30 / 50$ & Monolithic $^{\mathrm{a}}$ & $14.71^{\mathrm{b}}$ & 0.69 & 4.69 \\
\hline $30 / 100$ & Monolithic $^{\mathrm{a}}$ & $16.24^{\mathrm{b}}$ & 0.66 & 4.06 \\
\hline
\end{tabular}

${ }^{\mathrm{a}}$ This rupture mode was observed on each of the 5 specimens tested.

${ }^{\mathrm{b}}$ Since the corresponding rupture mode is monolithic, this result is a lower estimate of the interface bond strength in shear.

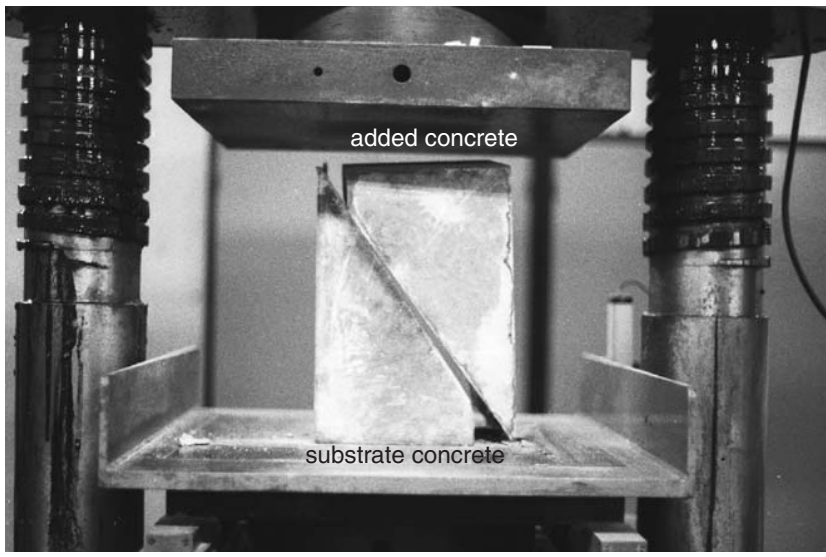

Fig. 1. Adhesive rupture mode of 30/30 slant shear specimens.

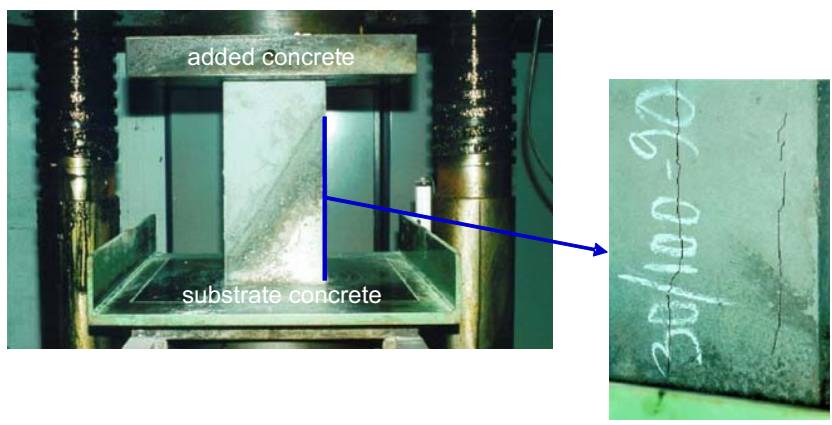

Fig. 2. Monolithic rupture mode of $30 / 50$ and 30/100 slant shear specimens.

from the compressive strength, according to Eurocode 2 [19].

The finite element analysis revealed an approximately uniform distribution of shear stresses in the interface for situation 30/30 (Fig. 4). For situation 30/50, a minor

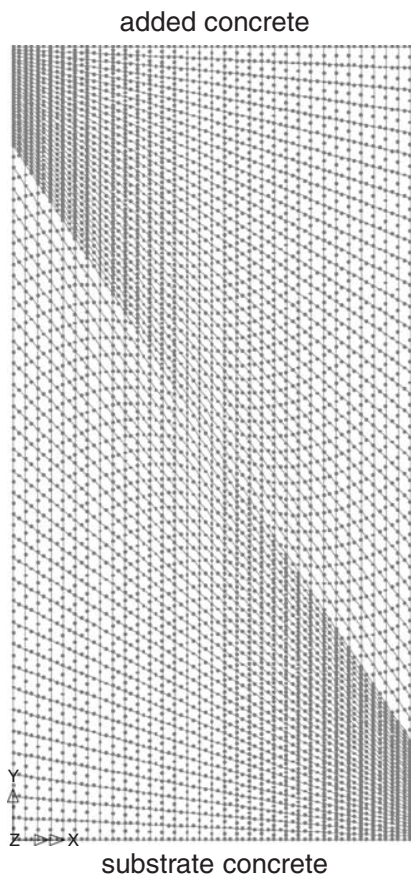

Fig. 3. Adopted mesh for finite element analysis of slant shear tests.

increase of the shear stress was observed from the top end to the bottom end of the interface (Fig. 4). This tendency was most significant for situation 30/100, presenting a stress peak (eventually from the numerical simulation) at the bottom end of the interface (Fig. 4). This could not justify the change in the rupture mode observed.

The numerical analysis also showed a distribution of compression normal stresses in the interface qualitatively similar to the corresponding distribution of shear stresses, for all considered situations (Fig. 5), but clearly increasing with the strength of the added concrete. 


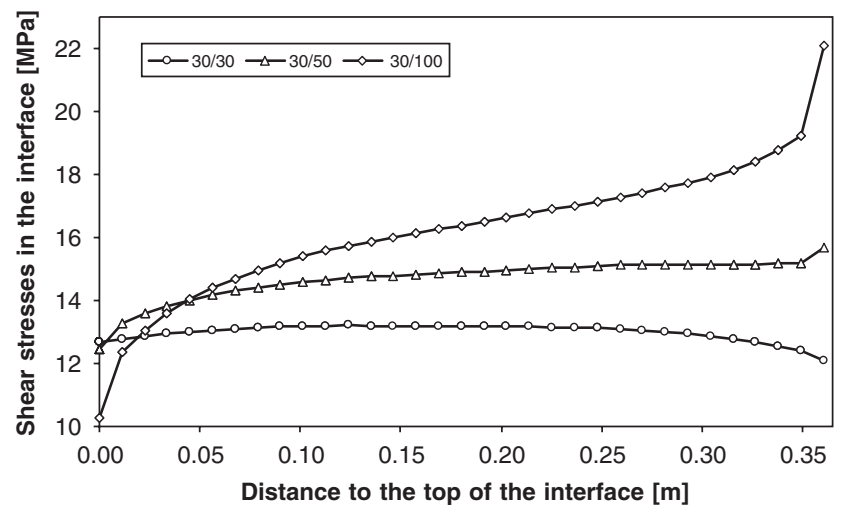

Fig. 4. Distribution of shear stresses in the interface.

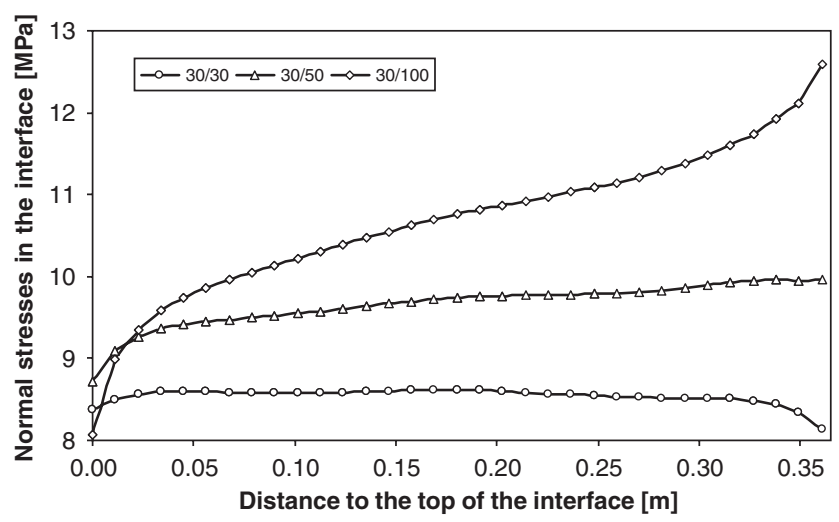

Fig. 5. Distribution of compression normal stresses in the interface.

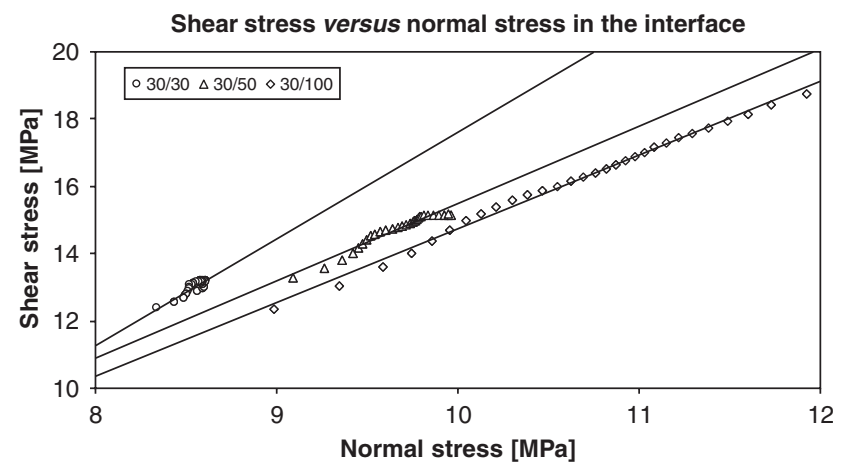

Fig. 6. Comparison shear stress versus normal stress in the interface.

Plotting normal stresses versus shear stresses in the interface (Fig. 6), and considering linear trend lines, it becomes clear that, for a given level of shear stress in the interface, the corresponding normal stress presents increasing values for situations 30/30, 30/50 and 30/ 100 , respectively, increasing the friction in the surface. This can explain the different rupture modes observed and previously referred to.
Relative to the design expression of Eurocode 2, it is seen that it may be conservative as the shear resistance is affected by the difference between the substrate concrete and the added concrete, increasing with the increasing strength of the latter.

\section{Conclusions and future research}

In slant shear tests it has been noticed an increment of bond strength in shear with the increase of compressive strength of added concrete. Furthermore, the rupture mode changed from adhesive, in $30 / 30$ specimens, to monolithic, in $30 / 50$ and $30 / 100$ specimens. A finite element analysis substantiated these results, showing that, increasing the difference between the compressive strengths of the concrete layers of the slant shear specimens, higher values of normal stress are present in the interface, for the same level of shear stress. Therefore, it was concluded that the added concrete compressive strength may have influence on concrete-to-concrete bond strength.

Following this conclusion, high-performance concrete shows advantages to carry out repairing and strengthening techniques involving adding new concrete to an existing concrete substrate.

In addition, design of shear at the interface between concrete cast at different times, according to Eurocode 2 , could be improved, since only the lowest strength concrete is considered.

Finally, results of slant shear tests must be carefully analysed, since substrate and added materials with different elasticity moduli change the stress distribution in the interface. This conclusion is also in agreement with the analysis performed by Austin et al. [31]. Moreover, according to this study, it is possible to select an angle that maximizes the likelihood of obtaining a bond failure. Therefore, in future research work, slant shear tests with different bond angles will be performed with the objective of obtaining adhesive ruptures for the same situations considered in the study described in this paper. Furthermore, tests on slabs strengthened with a new concrete layer will also be conducted, considering the same situations of increasing compressive strength of the new concrete layer, to compare the effect of modulus mismatch between slant shear tests and a real strengthening situation.

\section{Acknowledgements}

We are grateful to SIKA, HILTI, BETÃO LIZ, FIVINTE, DYWIDAG, PREGAIA, CIMPOR and SECIL for their collaboration in this research project. 


\section{References}

[1] Emmons PH. Concrete repair and maintenance. Part three: Surface repair, Section 6: bonding repair materials to existing concrete. MA: R.S. Means Company; 1994. p. 154-63.

[2] Rizzo EM, Sobelman MB. Selection criteria for concrete repair materials. Concrete International 1989; September:46-9.

[3] Talbot C, Pigeon M, Beaupré D, Morgan DR. Influence of surface preparation on long-term bonding of shotcrete. ACI Materials Journal 1994;November-December:560-6.

[4] Silfwerbrand J. Improving concrete bond in repaired bridge decks. Concrete International 1990; September:121-6.

[5] Hindo KR. In-place bond testing and surface preparation of concrete. Concrete International 1990;April:127-9.

[6] Júlio ES, Branco F, Silva VD. Concrete-to-concrete bond strength. Influence of an epoxy-based bonding agent on a roughened substrate surface, Thomas Telford. Magazine of Concrete Research 2005. (to be published in V. 57)

[7] Abu-Tair AI, Rigden SR, Burley E. Testing the bond between repair materials and concrete substrate. ACI Materials Journal 1996; November-December:553-8.

[8] Cleland DJ, Long AE. The pull-off test for concrete patch repairs. Proceedings of the Institution of Civil Engineers-Structures and Buildings 1997;122:451-60.

[9] Saucier F, Pigeon M. Durability of new-to-old concrete bondings. In: Proceedings of the ACI international conference evaluation and rehabilitation of concrete structures and innovations in design, vol. 1, Hong Kong, 1991, p. 689-707.

[10] Júlio ES, Branco F, Silva VD. Structural rehabilitation of columns with reinforced concrete jacketing. Progress in Structural Engineering and Materials 2003;5(1):29-37.

[11] Rodriguez M, Park R. Seismic load tests on reinforced concrete columns strengthened by jacketing. ACI Structural Journal 1994; 91(2):150-9.

[12] Hayashi T, Niwa H, Fukuhara M. Strengthening methods of the existing reinforced concrete buildings. In: Proceedings of the seventh world conference on earthquake engineering, vol. 4, Istanbul, 1980. p. 89-97.

[13] Bett BJ, Klingner RE, Jirsa JO. Lateral load response of strengthened and repaired reinforced concrete columns. ACI Structural Journal 1988;85(5):499-508.

[14] Gomes A, Appleton J. Experimental testing of strengthened columns subjected to cyclic loadings. Revista Portuguesa de Engenharia de Estruturas 1994;38:19-29 [in Portuguese].

[15] Ramirez JL, Barcena JM, Urreta JI, Sanchez JA, Hernandez B. Local repair of concrete columns with total compressive strength loss. Report T 2.3-09 BREU - P 3091, January 1992.

[16] Júlio ENBS. The influence of the interface on the behaviour of columns strengthened by RC Jacketing. Ph.D. thesis, Department of Civil Engineering, Faculty of Sciences and Technology, University of Coimbra, 2001 [in Portuguese].

[17] Júlio ES, Branco F, Silva VD. RC jacketing - interface influence on monotonic loading response. ACI Structural Journal 2005;102(2):252-7.

[18] Stoppenhagen DR, Jirsa JO, Wyllie Jr LA. Seismic repair and strengthening of a severely damaged concrete frame. ACI Structural Journal 1995;92(2):177-87.

[19] Eurocode 2: Design of concrete structures-Part 1.1: General rules and rules for buildings, April 2003.

[20] Júlio ES, Branco F, Silva VD. Influence of substrate surface roughness on concrete-to-concrete bond strength. Construction and Building Materials 2004;18(9):675-81.

[21] Lourenço JF. Concrete mix design. Instituto Superior de Engenharia de Coimbra, 1995 [in Portuguese].

[22] Larrard F. Design and properties of high performance concretes. Rapport de recherche LPC No. 149, Laboratoire Central des Ponts et Chaussées, Mars 1988 [in French].

[23] Sellevold EJ. The function of condensed silica fume in high strength concrete. In: Holand I, Helland S, Jakobsen B, Lenschow $\mathrm{R}$, editors, Utilization of high strength concrete, Symposium in Stavanger, Norway, June 15-18. Tapir, 1987. p. 39-49.

[24] Yogendran V, Langan BW, Ward MA. Utilization of silica fume in high strength concrete. In: Holand I, Helland S, Jakobsen B, Lenschow $\mathrm{R}$, editors. Utilization of high strength concrete, Symposium in Stavanger, Norway, June 15-18. Tapir, 1987, p. 85-97.

[25] Danielsen SW. Optimizing aggregate properties for highstrength concrete. In: Holand I, Helland S, Jakobsen B, Lenschow R, editors. Utilization of high strength concrete, Symposium in Stavanger, Norway, June 15-18. Tapir, 1987. p. 73-84.

[26] Chang T-P, Su N-K. Estimation of coarse aggregate strength in high-strength concrete. ACI Materials Journal 1996; January-February:3-9.

[27] Gutierrez PA, Canovas MF. High-performance concrete: requirements for constituent materials and mix proportioning. ACI Materials Journal 1996;May-June:233-41.

[28] Paillere AM. Role of admixtures and in particular of superplasticizers. Séminaire organisé par le Collège International des Sciences de la Construction, Conseil International de la Langue Française, Paris, 1987 [in French].

[29] Chan SYN, Feng NQ, Tsang MKC. Workability retention of high strength/superplasticized concrete. Magazine of Concrete Research 1996;48(177):301-9.

[30] Standard recommended practice for selecting proportions for concrete. ACI 613-54 1954;51(6):49-64.

[31] Austin S, Robins P, Pan Y. Shear bond testing of concrete repairs. Cement and Concrete Research 1999;29:1067-76. 